\title{
Policy-oriented parties and the choice between social and private insurance
}

\author{
Philippe De Donder \\ University of Toulouse (GREMAQ and IDEI) \\ Jean Hindriks \\ CORE, Catholic University of Louvain and Queen Mary, University \\ of London
}

June 2003

\begin{abstract}
We study the political economy of social insurance in a world where individuals differ in both income and risk. Social insurance is financed through distortionary taxation and redistributes across income and risk. Individuals vote on social insurance which they can complement with insurance bought on the private market. Private insurance is actuarially fair but suffers from adverse selection which results in a screening equilibrium with partial coverage. The equilibrium social insurance is the result of bi-partisan electoral competition game where parties maximize the utility of their members. We calculate the equilibrium social insurance offered by the two parties as well as their equilibrium membership, and study how the equilibrium outcome is affected by electoral uncertainty, distortions from taxation, risk aversion and the distribution of risk and income. We then calibrate the model to US data from the PSID survey. Lastly, we study how the political demand for social insurance is affected by the possibility to redistribute through income taxation.
\end{abstract}

Keywords:political economy, social insurance, redistribution, adverse selection.

JEL classification: $\mathrm{H} 23, \mathrm{H} 50$ 


\section{Introduction}

Insurance, although being a private good, is often publicly financed. As for health insurance, a recent OECD report reveals that for many countries a very high proportion of health spending were accounted for by the state (OECD Health Data 2001). According to this study in 1998 state spending as a proportion of total spending on health was $80 \%$ in Germany, $89 \%$ in France, $67 \%$ in the Netherlands, $67 \%$ in Italy, $73 \%$ in Austria, and $84 \%$ in Britain. In terms of total spending, Germany spent $10 \%$ of GDP on health, France spent $9.5 \%$ but Britain spent just 6.8\%. As for pensions, Börsch-Supan et al.(2001) report that the proportion of retirement benefits coming from public insurance was on average $85 \%$ in Germany, $65 \%$ in Great-Britain, $50 \%$ in the Netherlands, $45 \%$ in the US and $42 \%$ in Switzerland.

In this paper, we concentrate on cost insurance and study why a majority of voters may prefer at least part of their insurance to be publicly financed. We identify two reasons for this: redistribution and efficiency. Typically, social insurance contributions are not related to risk but rather to income levels. Social insurance thus implies redistribution in two ways with mandatory participation. First, there is redistribution from low to high risks because contributions do not depend on individual's morbidity or risk: higher-risk individuals pay less than their expected risk while lower-risk individuals pay more. Second, since contributions increase with income, higher-income individuals pay more than lower-income individuals even if they have the same risk. On the other hand, private insurance premia are unrelated to income, and private insurers have an incentive to screen clients according to their riskiness. Private insurance thus does not imply any (ex ante) redistribution. To accommodate these two sources of redistribution, we consider in this paper individuals differing both in their income and their risk of incurring the same damage.

A second reason to prefer social to private insurance is due to the presence of asymmetric information. It is indeed surprising that most contributions to the literature either ignore the problem of adverse selection by assuming perfect private insurance or assume pooling private insurance (see among others, Blomqvist and Horn, 1984; Cremer and Pestieau, 1996; Gouveia, 1997; Petretto, 1999; Rochet, 1991). However insurance is plagued with adverse selection, which makes voluntary insurance inefficient and provides an efficiency argument for compulsory social insurance.

We study here the situation where individuals vote over the social insurance coverage rate, while keeping the opportunity to voluntarily supple- 
ment this coverage rate on the private market. We have already studied this framework in De Donder and Hindriks (forthcoming). The main distinctive feature of our model is that we assume away the income effect in the demand for insurance so that we do not get the peculiarity that the poor favor less social insurance than the middle class. We do this by adopting Yaari (1987)'s dual theory of choice under uncertainty (i.e., risk aversion without diminishing marginal utility of income). Beside presenting independent interest, this modelling of risk aversion will allow the derivation of a rich set of insights that could hardly be obtained with the expected utility model.

We add two dimensions to our previous analysis. The first is that we assume here that financing public insurance is distortionary. This results in individuals having interior preferences for social insurance coverage rate. This is in sharp contrast with our previous analysis, where non distortionary taxation led to individuals having corner preferences, and so to the impossibility of a top-up system where partial social insurance coexists with private complementary insurance.

We have also added flesh to the political side of the model. The traditional Downsian model, where parties are only interested in winning the elections, predicts that parties will converge to the Condorcet winner (the option preferred by a majority to any other feasible option) if it exists. Real world observations suggest that parties do not converge. This can be due to the combination of two features. First, one can argue that parties are not only interested in winning the elections, but are also policy-motivated (if not, why do we talk about "left" and "right" parties?). Second, parties are uncertain as to the results of the elections. We add these two features to our model of electoral competition, assuming that two parties choose their political platform (the social insurance coverage rate) to maximize the utility of their members. We further assume that party memberships are endogenous. Following Roemer(2001), we call the political outcome an endogenous parties Wittman equilibrium (EPWE). We compute the EPWE for different distributions of risk and income and analyze the effects of a change in risk aversion, uncertainty, and distortion on the equilibrium outcome. We obtain among other results policy divergence that is increasing in the degree of electoral uncertainty.

The redistributive motive plays a crucial role in the political support for social insurance. One can claim that, in reality, the tax and transfer system, and not social insurance, is the mechanism most often used to redistribute income. We then study how the possibility of redistributing through linear income taxation would affect the political demand for social insurance. 
We obtain that a higher proportion of tax proceeds redistributed through transfers leads to a lower social insurance coverage rate.

The paper is organized as follows. Section 2 presents the social insurance model. Section 3 studies the Wittman political equilibrium outcome. Section 4 uses Panel data from the PSID on income levels and health expenditures for a sample of 6863 households and calculates the corresponding Wittman equilibria. Section 5 extends the model to allow for income tax redistribution and analyses its effect on the political equilibrium demand for social insurance. Section 6 concludes the paper.

\section{The model}

The economy is composed of individuals who differ in income $w$ and risk $\theta$ defined as the probability of incurring a damage normalized to one for all. There is a continuum of individuals, with the characteristics $w$ and $\theta$ continuously distributed on a unit square ${ }^{1}$ according to a joint distribution function $H(w, \theta)$. The marginal distribution of risks in the population is denoted by $F(\theta)$, with mean risk $\bar{\theta}=\int_{0}^{1} \theta d F(\theta)$ and median risk $\theta_{m}=F^{-1}(1 / 2)$. Income levels are distributed according to the marginal distribution function $G(w)$ with mean income $\bar{w}=\int_{0}^{1} w d G(w)$ and median income $w_{m}=G^{-1}(1 / 2)$.

We model individuals' risk preferences using Yaari (1987)'s theory, which is dual to the expected utility theory in the sense that it is linear in wealth but non linear in probabilities. We use this formulation because it allows us to separate attitude towards risk from attitude towards wealth: with Yaari's approach, risk aversion is entirely driven by a transformation of probabilities whereby bad outcomes are given high weight while good outcomes are given low weight. The insurance contracts we consider consist of a premium $\pi$ and a coverage rate $\delta \in[0,1]$ which is the proportion of the damage reimbursed. Following De Donder and Hindriks (forthcoming), the utility function of the individual of type $(w, \theta)$ from insurance contract $(\pi, \delta)$ is

$$
u(\pi, \delta ; w, \theta)=w-\pi-(1+\alpha)(1-\delta) \theta
$$

where $\alpha \geq 0$ is a risk aversion parameter. In words, the individual overestimates by a fraction $\alpha$ her expected financial damage. The utility without insurance is

$$
u(0,0 ; w, \theta)=w-(1+\alpha) \theta
$$

\footnotetext{
${ }^{1}$ This assumption is done to simplify notations. See De Donder and Hindriks (forthcoming) for arbitrary lower and upperbounds of the distributions.
} 
and the reservation premium is

$$
r(\theta)=(1+\alpha) \theta \delta .
$$

Therefore risk aversion $\alpha$ in our model takes the form of a relative markup over the actuarially fair price. Making $\alpha$ independent of $w$ accords with our desire to disentangle risk aversion from income and will greatly simplify the analysis by eliminating income effect in the demand of insurance. ${ }^{2}$

There exist two kinds of insurance in this economy. Compulsory social insurance offers coverage $\delta$ and is financed through income taxation: its price $\pi(\delta, w)$ is proportional to income (which is observed by the taxing authority) but independent of individual risks. We assume that income taxation is distortionary and adopt a short cut formulation for this distortion. More precisely, for an individual with income $w$, the social premium (tax bill) is $\pi(\delta, w)=(1+\eta \delta) \delta \bar{\theta} w / \bar{w}$ for a coverage rate $\delta \in[0,1]$, with the parameter $\eta \geq 0$ denoting the deadweight loss from taxation.

Individuals can possibly supplement this social insurance with private insurance. Individual risks are private information, and insurance firms can only observe their marginal distribution $F(\theta)$. Faced with this adverse selection problem, firms propose insurance contracts differing in coverage rate to separate buyers according to their risk. Perfect competition between private insurers ensures that buyers pay actuarially fair premia. Formally, we denote by $\delta(\theta)$ the total coverage for type $\theta$ where the extra private coverage $\delta(\theta)-\delta$ is purchased at a fair price $(\delta(\theta)-\delta) \theta$ and satisfies the incentive compatibility constraints. The corresponding payoff for an individual with risk $\theta$ and income $w$ is,

$$
\begin{aligned}
& v(\delta ; w, \theta) \\
= & w(1-(1+\eta \delta) \delta \bar{\theta} / \bar{w})-(\delta(\theta)-\delta) \theta-(1+\alpha)(1-\delta(\theta)) \theta .
\end{aligned}
$$

We now derive the equilibrium menu of contracts for the private insurers. In any separating equilibrium, no type $\theta$ can benefit from claiming to be a different type $\widehat{\theta}$. Thus, the following necessary local incentive compatibility condition must hold: for all $\theta \in \Theta$

$$
\left[\frac{\partial v(\delta ; w, \theta)}{\partial \hat{\theta}}\right]_{\hat{\theta} \rightarrow \theta}=\alpha \theta \delta^{\prime}(\theta)-(\delta(\theta)-\delta)=0 .
$$

\footnotetext{
${ }^{2}$ Equation (2) implies that it can be optimal under dual theory to buy full insurance even above the actuarially fair price. As first pointed out by $\operatorname{Mossin}(1968)$, this cannot be the case with expected utility theory. Casual observation suggests that dual theory is more in line with reality on this point.
} 
Hence the separating equilibrium coverage rate function $\delta(\theta)$ solves the following differential equation,

$$
\delta^{\prime}(\theta)=\frac{\delta(\theta)}{\alpha \theta}-\frac{\delta}{\alpha \theta} \quad \forall \theta
$$

Optimality requires setting $\delta(\theta)=1$ for $\theta=1$ and so, the unique solution is,

$$
\delta(\theta)=\delta+(1-\delta) \theta^{1 / \alpha}
$$

Notice that in equilibrium, for all types total coverage is increasing with social insurance coverage $\delta$ since $\theta^{1 / \alpha}<1$ for all $\theta<1$. Hence private insurance decisions are affected by the level of social insurance coverage but there is no complete crowding out of private insurance by social insurance.

Inserting this equilibrium policy into the payoff function we get the indirect utility function

$$
\begin{aligned}
v(\delta ; w, \theta)= & w(1-(1+\eta \delta) \delta \bar{\theta} / \bar{w})-(1-\delta) \theta^{1 / \alpha} \theta \\
& -(1+\alpha) \theta\left(1-(1-\delta) \theta^{1 / \alpha}-\delta\right) \\
= & w(1-(1+\eta \delta) \delta \bar{\theta} / \bar{w})-(1-\delta) \theta(1+\varphi(\alpha, \theta))
\end{aligned}
$$

where $\varphi(\alpha, \theta) \equiv \alpha\left(1-\theta^{1 / \alpha}\right) \geq 0$ is the efficiency gain from social insurance as measured by the extra coverage $1-\theta^{1 / \alpha}$ evaluated according to the degree of risk aversion $\alpha$.

We now study individual preferences over social insurance. Differentiating the payoff functions with respect to $\delta$ we get

$$
\frac{\partial v(\delta ; w, \theta)}{\partial \delta}=\theta(1+\varphi(\alpha, \theta))-w(1+2 \eta \delta) \bar{\theta} / \bar{w}
$$

and $\frac{\partial^{2} v(\delta ; \theta, w)}{\partial \delta^{2}}<0$ so the payoff function is concave with respect to $\delta$ for all $(w, \theta)$. We see that although individuals are identified by two characteristics $(\theta, w)$, their preferences over social insurance can be summarized by a single parameter

$$
t(w, \theta)=\frac{w}{\theta(1+\varphi(\alpha, \theta))} .
$$

We refer to this parameter as a type aggregator (Shapiro, 1999) which is increasing in $w$ and decreasing in $\theta$. Low type $t$ includes poor and high risk individuals whereas high type $t$ includes rich and low risk individuals. Using the type aggregator $t$, we have 


$$
\frac{\partial v(\delta ; t(w, \theta))}{\partial \delta}=\left[\frac{1}{t(w, \theta)}-(1+2 \eta \delta) \frac{\bar{\theta}}{\bar{w}}\right] w
$$

Define $\underline{t} \equiv \bar{w} /(1+2 \eta) \bar{\theta}$ and $\bar{t} \equiv \bar{w} / \bar{\theta}$, then the optimal amount of public coverage for a type $t(w, \theta)$ individual can be expressed as

$$
\delta^{*}(t(w, \theta))=\left\{\begin{array}{lr}
1 & \text { for } t(w, \theta) \leq \underline{t} \\
\frac{\bar{w} / \bar{\theta}}{2 \eta}\left[\frac{1}{t(w, \theta)}-\frac{\bar{\theta}}{\bar{w}}\right] & \text { for } \underline{t}<t(w, \theta)<\bar{t} \\
0 & \text { for } t(w, \theta) \geq \bar{t}
\end{array}\right.
$$

Thus preference for social insurance is decreasing with $t$. It is lower for high income and low risk individuals. Also observe that more risk aversion $\alpha$ increases the efficiency gain from social insurance and leads to higher preferences for social insurance. Finally, note that $\underline{t}=\bar{t}$ when $\eta=0$ leading to $\delta^{*}(t(w, \theta))=\{0,1\}$ : individuals prefer either full public insurance or no public insurance at all in absence of distortions (see De Donder and Hindriks, proposition 3).

The utility function is everywhere increasing on $\delta \in[0,1]$ for individuals with $t(w, \theta) \leq \underline{t}$, everywhere decreasing for individuals with $t(w, \theta) \geq \underline{t}$ and single-peaked with an interior maximum for other individuals. It is also easily verified that utility functions are symmetric. From the median voter theorem, the Condorcet winning coverage rate is that preferred by the individuals with the median value of $t(w, \theta)$. This value of the coverage rate is the equilibrium of a Downsian electoral competition game between two political parties only interested in winning the elections.

In the following sections we depart from the Downsian model by assuming that parties are not only interested in winning the election but that they are also policy motivated. In this Wittman model, parties are interested in maximizing the utility of their members. With this political game we obtain policy divergence contrarily to the Downs model where parties converge inevitably to the Condorcet winner.

\section{Wittman equilibria with endogenous parties}

We assume that two political parties (denoted $L$ and $R$ ) compete for votes in an election under the plurality rule. Both parties simultaneously choose the social insurance coverage rate as their political platform. Individuals vote for the platform they prefer. The party with the most votes wins the election and implements its platform. 
Unlike Downsian political competition, we assume that parties have policy preferences represented by the average utility of their members (see Wittman, 1973). Without electoral uncertainty, utility-maximizing parties would inevitably converge to the Condorcet winner as predicted by Downs' model. Indeed to have any influence on the implemented policy, a party must win the election and propose the Condorcet winner (if it exists), regardless of its policy preferences (see Roemer, 2001). To allow parties to depart from the condorcet winner and no forego any chance of reelection, we must introduce some uncertainty in the electoral outcome. This uncertainty, together with utility maximizing parties, gives rise to the following trade-off: by departing from the Condorcet winner a party decreases its chances of being elected but may increase the utility of its members if elected.

Define individual preferences over coverage $\delta$ as $v(\delta ; t(w, \theta))$. Let $\Omega\left(\delta, \delta^{\prime}\right)$ be the set of individuals who prefer $\delta$ to $\delta^{\prime}$ :

$$
\Omega\left(\delta, \delta^{\prime}\right)=\left\{(w, \theta): v(\delta ; t(w, \theta)) \geq v\left(\delta^{\prime} ; t(w, \theta)\right)\right\} .
$$

Let $H\left(\Omega\left(\delta, \delta^{\prime}\right)\right)$ be the measure of this set. In absence of electoral uncertainty, this measure would represent the proportion of votes a party proposing $\delta$ would obtain when faced with an opponent advocating $\delta^{\prime}$. It seems more in line with reality to assume that parties are uncertain as to the precise result of the election even after platforms are announced. One reason may be that platforms are announced months before the elections and that voters' views change during the process of debate between parties. Another possibility is that parties are uncertain as to which voters will turn out at the pools. To formalize this uncertainty, we use the "error-distribution model of uncertainty" where parties assume that the proportion of votes for $\delta$ lies in the interval $\left(H\left(\Omega\left(\delta, \delta^{\prime}\right)\right)-\Delta, H\left(\Omega\left(\delta, \delta^{\prime}\right)\right)+\Delta\right)$ for some $\Delta>0$ and is distributed uniformly on this interval (see Roemer, 2001). Thus, the probability that $\delta$ defeats $\delta^{\prime}$ is ${ }^{3}$

$$
p\left(\delta, \delta^{\prime}\right)=\left\{\begin{array}{ccc}
0 & \text { if } H\left(\Omega\left(\delta, \delta^{\prime}\right)\right)+\Delta \leq 1 / 2 \\
& \frac{H\left(\Omega\left(\delta, \delta^{\prime}\right)\right)+\Delta-1 / 2}{2 \Delta} & \text { otherwise } \\
1 & \text { if } H\left(\Omega\left(\delta, \delta^{\prime}\right)\right)-\Delta \geq 1 / 2
\end{array}\right.
$$

For any $H\left(\Omega\left(\delta, \delta^{\prime}\right)\right) \in \frac{1}{2} \pm \Delta$, the probability that $\delta$ defeats $\delta^{\prime}$ is a smooth function of the policy pair. Party $L$ defeats party $R$ with probability $p\left(\delta^{L}, \delta^{R}\right)$ and is defeated by party $R$ with probability $p\left(\delta^{R}, \delta^{L}\right)=1-$ $p\left(\delta^{L}, \delta^{R}\right)$.

\footnotetext{
${ }^{3}$ If $\delta=\delta^{\prime}, p\left(\delta, \delta^{\prime}\right)=1 / 2$.
} 
Both parties simultaneously choose a platform in order to maximize the average utility of their members, given the platform proposed by the other party. We assume that parties' preferences is consitent with the dual theory and take the form of a weighted sum of the average utility of their members, with a mark-up on the probability that the other party gets elected. Each party's membership is endogenous and composed of those individuals who prefer the party's platform to the one proposed by its opponent. In an Endogenous Parties Wittman Equilibrium (EPWE)

- No party wants to change its platform given the platform of the other party and its membership;

- No individual wants to change membership given the platforms proposed by the two parties.

We now give the formal definition of an (EPWE). Notice that the set of agents preferring policy $\delta^{L}$ to $\delta^{R}$ (with $\delta^{L}>\delta^{R}$ ) are those types below the threshold $t^{\circ}\left(\delta^{L}, \delta^{R}\right)$.

Definition 1 An Endogenous Parties Wittman Equilibrium (EPWE) is a pair $\left(\delta^{L}, \delta^{R}\right) \in[0,1]^{2}$ with $\delta^{L} \geq \delta^{R}$ such that

$$
\begin{aligned}
& \delta^{L}=\arg \max \phi\left(p\left(\delta^{R}, \delta^{L}\right) V^{L}\left(\delta^{R}\right)+\left(1-\phi\left(p\left(\delta^{R}, \delta^{L}\right)\right)\right) V^{L}\left(\delta^{L}\right),\right. \\
& \delta^{R}=\arg \max \phi\left(p\left(\delta^{L}, \delta^{R}\right)\right) V^{R}\left(\delta^{L}\right)+\left(1-\phi\left(p\left(\delta^{L}, \delta^{R}\right)\right)\right) V^{R}\left(\delta^{R}\right),
\end{aligned}
$$

where political risk aversion translates into political parties putting more weight on the probability of loosing the election $\phi(p())=.\left(1+\alpha_{p}\right) p($.$) , and$ where the utility function of each party is

$$
\begin{aligned}
V^{L}(\delta) & =\int_{L} v(\delta ; t(w, \theta)) d H(w, \theta) ; \\
V^{R}(\delta) & =\int_{R} v(\delta ; t(w, \theta)) d H(w, \theta)
\end{aligned}
$$

with their (endogenous) membership

$$
\begin{aligned}
L & =\left\{(w, \theta): t(w, \theta) \leq t^{\circ}\left(\delta^{L}, \delta^{R}\right)\right\} \\
R & =\left\{(w, \theta): t(w, \theta)>t^{\circ}\left(\delta^{L}, \delta^{R}\right)\right\}
\end{aligned}
$$

and the critical type $t(w, \theta)=t^{\circ}\left(\delta^{L}, \delta^{R}\right)$ solving

$$
v\left(\delta^{L} ; t(w, \theta)\right)=v\left(\delta^{R} ; t(w, \theta)\right) .
$$


Using our economic model, we can write down explicitly the type $t(w, \theta)=$ $t^{\circ}\left(\delta^{L}, \delta^{R}\right)$ who is indifferent between $\delta^{L}$ and $\delta^{R}$ :

$$
t^{\circ}\left(\delta^{L}, \delta^{R}\right)=\frac{\bar{w} / \bar{\theta}}{1+\eta\left(\delta^{L}+\delta^{R}\right)}
$$

Due to the symmetry of preferences, the critical type is unchanged with symmetric differentiation of policies. Symmetry further implies that all individuals with type $t(w, \theta) \leq t^{\circ}\left(\delta^{L}, \delta^{R}\right)$ prefer $\delta^{L}$ to $\delta^{R}$ if $\delta^{L}>\delta^{R}$. Party $L$ represents low types and party $R$ represents high types.

Each party chooses its policy taking the policy of the other party as given. The first-order conditions for a Wittman equilibrium policy pair $\left(\delta^{L}, \delta^{R}\right)$ are

$$
\begin{aligned}
& \left(1-\phi\left(p\left(\delta^{R}, \delta\right)\right)\right) \frac{\partial V^{L}(\delta)}{\partial \delta}-\frac{\partial \phi\left(p\left(\delta^{R}, \delta\right)\right)}{\partial \delta}\left[V^{L}(\delta)-V^{L}\left(\delta^{R}\right)\right]=0 \\
& \left(1-\phi\left(p\left(\delta^{L}, \delta\right)\right)\right) \frac{\partial V^{R}(\delta)}{\partial \delta}-\frac{\partial \phi\left(p\left(\delta^{L}, \delta\right)\right)}{\partial \delta}\left[V^{R}(\delta)-V^{R}\left(\delta^{L}\right)\right]=0
\end{aligned}
$$

Hence, the effect of a change in the social coverage rate proposed by one party can be decomposed into the sum of two parts: (i) a change in the utility level of its members given the set of types choosing to support that party, and (ii) a change in the set of voters supporting that party and thus in the chance of its policy being implemented.

We can now calculate the Wittman equilibria. The Tables below report the Wittman equilibria for various distributions of types and different values of the distortion, risk aversion and uncertainty parameters. Throughout we assume that $w$ and $\theta$ are independently distributed and moreover that $\theta$ is uniformly distributed. In Tables $1 \mathrm{a}, \mathrm{b}, w$ is uniformly distributed while in Tables 2a,b, income is distributed according to a positively skewed $\operatorname{Beta}(2,5)$ distribution. Tables $1 \mathrm{a}$ and $2 \mathrm{a}$ give results with the same economic and political risk aversion: $\alpha=\alpha_{p}=0.1$. This assumption seems reasonable since parties merely aggregate the utility of their members. On the other hand, one can argue that the two parameters concern two distinct risks: the (economic) risk to incur a damage for $\alpha$ and the (political) risk of losing the elections for $\alpha_{p}$. We then report in Tables $1 \mathrm{~b}$ and $2 \mathrm{~b}$ results obtained with a higher political risk aversion $\alpha_{p}=0.3>\alpha=0.1$. Each Table covers various degrees of distortion $\eta \in\{0.1,0.3,0.5\}$ and uncertainty $\Delta \in\{0.001,0.01,0.1\}$ For each configuration of parameters, each 
Table reports the Wittman equilibrium policy pair $\left(\delta^{L}, \delta^{R}\right)$, the probability that party $L$ wins the election, $p\left(\delta^{L}, \delta^{R}\right)$, and the expected policy outcome, $p\left(\delta^{L}, \delta^{R}\right) \delta^{L}+\left(1-p\left(\delta^{L}, \delta^{R}\right)\right) \delta^{R}$.

First observe that, in absence of uncertainty both parties propose the Condorcet winning policy $\delta_{m}$. When political uncertainty increases, the equilibrium policies diverge with $\delta^{L}>\delta_{m}>\delta^{R}$, party $L$ representing poor/high risk voters who want more social insurance and party $R$ representing rich/low risk voters who want less social insurance. The intuition is simply that uncertainty reduces the electoral cost of departing from the Condorcet winner and enables parties to propose a policy closer to what they members whish. Not surprisingly, a similar effect arises when political aversion decreases, since parties then care less about the possibility of losing election.

We also note that, as long as parties propose interior policies, they attract the same number of voters and so they tie for winning. This result is not surprising with symmetric preferences and distribution functions (Tables 1a and $1 \mathrm{~b}$ ) but is more surprising with a positively skewed distribution of risks (Tables $2 \mathrm{a}$ and $2 \mathrm{~b}$ ). An important consequence is that the expected policy is not affected by the amount of political uncertainty, but only the equilibrium platforms proposed by the parties. However with non-interior equilibrium, the party which is constrained is more likely to win election. The reason is that such party would have liked to move further away from the Condorcet winner, even at the cost of a lower probability of winning.

We also obtain that equilibrium policies decrease with the degree of distortion $\eta$ of social insurance and increase with economic risk aversion. The latter effect is driven by the fact that risk aversion (parameter $\alpha$ ) increases everybody's preferences for social insurance. Finally, comparing Tables 1 and 2, we see that the positive skewness of the income distribution induces both parties to propose more social insurance in equilibrium. This is because a higher proportion of voters is below the mean income and benefits from the income redistribution associated with social insurance. 
Table 1a: Wittman equilibrium with independent and uniform distribution of income and risk and $\alpha=\alpha_{p}=0.1$.

\begin{tabular}{|c|c||c|c|c|c|}
\hline$\Delta$ & $\eta$ & $\delta^{L}$ & $\delta^{R}$ & $p\left(\delta^{L}, \delta^{R}\right)$ & $E\left(\delta^{L}, \delta^{R}\right)$ \\
\hline \hline 0.1 & 0.1 & $100 \%$ & $0 \%$ & $46.21 \%$ & $46.21 \%$ \\
\hline & 0.3 & $42.88 \%$ & $0 \%$ & $39.96 \%$ & $17.14 \%$ \\
\hline & 0.5 & $25.73 \%$ & $0 \%$ & $39.96 \%$ & $10.28 \%$ \\
\hline \hline 0.01 & 0.1 & $50.39 \%$ & $33.09 \%$ & $50 \%$ & $41.68 \%$ \\
\hline & 0.3 & $16.80 \%$ & $11.03 \%$ & $50 \%$ & $13.89 \%$ \\
\hline & 0.5 & $10.08 \%$ & $6.62 \%$ & $50 \%$ & $8.34 \%$ \\
\hline \hline 0.001 & 0.1 & $42.55 \%$ & $40.78 \%$ & $50 \%$ & $41.68 \%$ \\
\hline & 0.3 & $14.18 \%$ & $13.59 \%$ & $50 \%$ & $13.89 \%$ \\
\hline & 0.5 & $8.51 \%$ & $8.16 \%$ & $50 \%$ & $8.34 \%$ \\
\hline
\end{tabular}

Table 1b: Wittman equilibrium with independent and uniform distribution of income and risk, $\alpha=0.1$ and $\alpha_{p}=0.3$.

\begin{tabular}{|c|c||c|c|c|c|}
\hline$\Delta$ & $\eta$ & $\delta^{L}$ & $\delta^{R}$ & $p\left(\delta^{L}, \delta^{R}\right)$ & $E\left(\delta^{L}, \delta^{R}\right)$ \\
\hline \hline 0.1 & 0.1 & $96.69 \%$ & $0.00 \%$ & $46.96 \%$ & $45.40 \%$ \\
\hline & 0.3 & $32.23 \%$ & $0.00 \%$ & $46.96 \%$ & $15.13 \%$ \\
\hline & 0.5 & $19.34 \%$ & $0.00 \%$ & $46.96 \%$ & $9.08 \%$ \\
\hline \hline 0.01 & 0.1 & $47.44 \%$ & $35.96 \%$ & $50 \%$ & $41.68 \%$ \\
\hline & 0.3 & $15.81 \%$ & $11.99 \%$ & $50 \%$ & $13.89 \%$ \\
\hline & 0.5 & $9.49 \%$ & $7.19 \%$ & $50 \%$ & $8.34 \%$ \\
\hline \hline 0.001 & 0.1 & $42.25 \%$ & $41.08 \%$ & $50 \%$ & $41.68 \%$ \\
\hline & 0.3 & $14.08 \%$ & $13.69 \%$ & $50 \%$ & $13.89 \%$ \\
\hline & 0.5 & $8.45 \%$ & $8.22 \%$ & $50 \%$ & $8.34 \%$ \\
\hline
\end{tabular}

Table 2a: Wittman equilibrium with $\operatorname{Beta}(2,5)$ distribution of income, uniform distribution of risk and $\alpha=\alpha_{p}=0.1$

\begin{tabular}{|c|c||c|c|c|c|}
\hline$\Delta$ & $\eta$ & $\delta^{L}$ & $\delta^{R}$ & $p\left(\delta^{L}, \delta^{R}\right)$ & $E\left(\delta^{L}, \delta^{R}\right)$ \\
\hline \hline 0.1 & 0.1 & $100 \%$ & $0 \%$ & $51.88 \%$ & $51.88 \%$ \\
\hline & 0.3 & $48.78 \%$ & $0 \%$ & $42.67 \%$ & $20.81 \%$ \\
\hline & 0.5 & $29.27 \%$ & $0 \%$ & $42.67 \%$ & $12.49 \%$ \\
\hline \hline 0.01 & 0.1 & $64.65 \%$ & $44.84 \%$ & $50 \%$ & $54.68 \%$ \\
\hline & 0.3 & $21.55 \%$ & $14.95 \%$ & $50 \%$ & $18.23 \%$ \\
\hline & 0.5 & $12.93 \%$ & $8.97 \%$ & $50 \%$ & $10.94 \%$ \\
\hline \hline 0.001 & 0.1 & $55.68 \%$ & $53.65 \%$ & $50 \%$ & $54.68 \%$ \\
\hline & 0.3 & $18.56 \%$ & $17.88 \%$ & $50 \%$ & $18.23 \%$ \\
\hline & 0.5 & $11.14 \%$ & $10.73 \%$ & $50 \%$ & $10.94 \%$ \\
\hline
\end{tabular}


Table 2b: Wittman equilibrium with $\operatorname{Beta}(2,5)$ distribution of income, uniform distribution of risk, $\alpha=0.1$ and $\alpha_{p}=0.3$.

\begin{tabular}{|c|c||c|c|c|c|}
\hline$\Delta$ & $\eta$ & $\delta^{L}$ & $\delta^{R}$ & $p\left(\delta^{L}, \delta^{R}\right)$ & $E\left(\delta^{L}, \delta^{R}\right)$ \\
\hline \hline 0.1 & 0.1 & $100 \%$ & $0.00 \%$ & $51.88 \%$ & $51.88 \%$ \\
\hline & 0.3 & $38.19 \%$ & $0.45 \%$ & $48.68 \%$ & $18.82 \%$ \\
\hline & 0.5 & $22.91 \%$ & $0.27 \%$ & $48.68 \%$ & $11.29 \%$ \\
\hline \hline 0.01 & 0.1 & $61.28 \%$ & $48.12 \%$ & $50 \%$ & $54.68 \%$ \\
\hline & 0.3 & $20.43 \%$ & $16.04 \%$ & $50 \%$ & $18.23 \%$ \\
\hline & 0.5 & $12.26 \%$ & $9.62 \%$ & $50 \%$ & $10.94 \%$ \\
\hline \hline 0.001 & 0.1 & $55.34 \%$ & $54.00 \%$ & $50 \%$ & $54.68 \%$ \\
\hline & 0.3 & $18.45 \%$ & $18.00 \%$ & $50 \%$ & $18.23 \%$ \\
\hline & 0.5 & $11.07 \%$ & $10.80 \%$ & $50 \%$ & $10.94 \%$ \\
\hline
\end{tabular}

In the next section, we calibrate our model using US panel data and compute the corresponding EPWE.

\section{Empirical analysis}

We first describe how we have used data from the Panel Study of Income Dynamics (PSID) to gather information on income levels and health expenditures for a sample of 6863 households. We then calibrate our model to calculate the Wittman equilibrium.

\subsection{Data on the distribution of risks and incomes}

To calibrate our model, we need information on both income and risk distributions. The unit of observation we use is the household. As a measure of income, we use the 1998 total family income as reported in the 1999 "Income plus" PSID data base (variable Faminc99). This variable measures the sum of taxable income of head and wife, transfer income of head and wife, taxable and transfer incomes of other family unit members, and social security income. Among respondents to this question, the average family income is $\$ 52,200$ and the median income is $\$ 38,300$.

As for risks, we concentrate on medical care costs. We first gather information on medical care costs incurred by these families in 1999 and 2000. These costs are obtained from the 2001 "Core family data" (variable ER19860) and consist of out-of-pocket costs plus the costs covered by Medicare, Medicaid, or other health insurance. The events covered are hospital 
and nursing home stays, doctor and clinic visits, outpatient surgery, dental visits, prescriptions, and in-home medical care. We obtain the following distribution of medical care costs.

Table 3: Distribution of medical care costs in 1999 and 2000

\begin{tabular}{|l|r|}
\hline less than $1,000 \$$ & $15.60 \%$ \\
\hline $1,000-5,000 \$$ & $31.00 \%$ \\
\hline $5,000-25,000 \$$ & $34.60 \%$ \\
\hline $25,000-100,000 \$$ & $9.45 \%$ \\
\hline $100,000-500,000 \$$ & $1.50 \%$ \\
\hline more than $500,000 \$$ & $0.25 \%$ \\
\hline no response & $7.60 \%$ \\
\hline
\end{tabular}

We keep in our database the 6863 households who have answered both questions (on income and health costs). We are not directly interested in the health costs, but in the risk to incur such costs. Our model uses a binary description of events (damage or no damage) while the PSID gives us some information on the size of the damage. To calibrate our model, we consider that a damage occurs if household medical care costs in 1999 and 2000 are greater than a threshold. We consider two distinct thresholds: 5,000 $\$$ and $25,000 \$$. For the low threshold, $45.8 \%$ of households have incurred a damage, and this proportion is $11.2 \%$ for the high threshold.

For each household, we know its 1998 income and whether it has incurred a damage in 1999 and 2000. We then translate this binary information into a probability in 1998 to incur the damage in the following years. We then compute, for each percentile of the income distribution, the proportion of households incurring the damage. This proportion is then used as the proxy for the risk probability of all households in income group. The joint distribution of risk and income we obtain exhibits a correlation between income and risk of -0.10 for the low cost definition and 0.08 for the high one.

\subsection{Wittman equilibria}

Given the discrete distribution of risk and income we cannot use the firstorder approach to calculate the Wittman equilibria. We briefly explain the algorithm used before reporting our results. 
We exploit the feature of the model that, in equilibrium, the median type individuals are indifferent between the policies proposed by the two parties. ${ }^{4}$ Formally, we calculate the function $m(\delta)$ which is such that

$$
v\left(\delta ; t_{m}\right)=v\left(m(\delta) ; t_{m}\right)
$$

where $t_{m}$ is the median type. Since preferences are single-peaked, we have that

$$
\delta \geq \delta_{m} \Leftrightarrow m(\delta) \leq \delta_{m}
$$

where $\delta_{m}$ denotes the policy most favored by the median type (i.e. the Condorcet winner). We know that at equilibrium $\delta^{L} \leq \delta_{m} \leq \delta^{R}$. We then use the following algorithm.

Step 0: Start with $\delta^{L}=\delta_{m}$.

Step 1: Compute $\delta^{R}=m\left(\delta^{L}\right)$.

Step 2: Verify that the left party has no incentive to deviate. That is, study small deviations around $\delta^{L}$ and compute the impact on the probability of winning the elections and on the average utility of its members. If the average utility of its members does not increase for any small deviation around $\delta^{L}$, the EPWE has been found and the procedure stops. If one deviation at least increases this utility, increase slightly the value of $\delta^{L}$ and go back to Step 1.

Using this algorithm, we have calculated the equilibrium policy pair for different values of the parameters. Table 4 summarizes the results we obtain with the two definitions of the damage and with two different political risk aversion.

Table 4: EPWE with PSID data (with $\alpha=0.05, \eta=0.4, \Delta=0.1$ )

\begin{tabular}{|l|l|l|l|}
\hline$\alpha_{p}$ & $\delta^{L}$ & $\delta^{R}$ & $\delta_{m}=E\left(\delta^{L}, \delta^{R}\right)$ \\
\hline & \multicolumn{4}{|c|}{ Low definition of damage } \\
\hline 0 & $56.7 \%$ & $39.3 \%$ & $48 \%$ \\
\hline 0.05 & $55.9 \%$ & $40.1 \%$ & $48 \%$ \\
\hline & \multicolumn{4}{|c|}{ High definition of damage } \\
\hline 0 & $62.8 \%$ & $12.4 \%$ & $37.6 \%$ \\
\hline 0.05 & $60.8 \%$ & $14.4 \%$ & $37.6 \%$ \\
\hline
\end{tabular}

As previously, we obtain that with political risk aversionthe equilibrium outcome is closer to the Condorcet winner. Comparing the results obtained

\footnotetext{
${ }^{4}$ Equivalently this means that at equilibrium party $L$ 's membership is composed of all types lower than the median type and party $R$ of all types above the median. Hence, each party has a $50 \%$ chance of winning the elections at equilibrium.
} 
with the two definitions of the damage, we see that the Condorcet winning coverage rate decreases when the damage is high, but the policy proposed by the left party actually increases!

\section{Tax and insurance mix}

In this section we study how the possibility of redistributing through linear income taxation would affect the political demand for social insurance. Consider a proportional tax rate $T$ used to finance both a lump sum transfer $G$ to everyone and insurance coverage $\delta$. In our model there is no income effect in the demand for insurance and so the utility function of type $(w, \theta)$ is

$$
v(T, \lambda ; w, \theta)=(1-T) w+G-(\delta(\theta)-\delta) \theta-(1+\alpha)(1-\delta(\theta)) \theta
$$

where $\delta(\theta)=\delta+(1-\delta) \theta^{1 / \alpha}$. We assume a quadratic deadweight loss from taxation yielding average tax revenue

$$
\left(1-\frac{T}{2}\right) T \bar{w}
$$

which is used for redistribution in proportion $\lambda$ and insurance provision in proportion $1-\lambda$. It follows that

$$
\begin{aligned}
G & =\lambda\left(1-\frac{T}{2}\right) T \bar{w} \\
\delta & =(1-\lambda)\left(1-\frac{T}{2}\right) T \bar{w} / \bar{\theta}
\end{aligned}
$$

Substituting for $G$ and $\delta$ into the utility function and rearranging we have

$$
\begin{aligned}
v(T, \lambda ; w, \theta)= & (1-T) w+\lambda\left(1-\frac{T}{2}\right) T \bar{w} \\
& -\left(1-\left((1-\lambda)\left(1-\frac{T}{2}\right) T \bar{w} / \bar{\theta}\right)\right)(1+\varphi) \theta
\end{aligned}
$$

We have essentially two degrees of freedom: the tax rate $T$ and revenue share, $\lambda$. Once these two are known, we can deduce from the government budget constraint both the transfer and the provision of social insurance. We first study the preferences over $T$. 
To study the preferences over $T$, we differentiate (3) with respect to the tax rate:

$$
\frac{\partial v(T, \lambda ; w, \theta)}{\partial T}=(1-T) \bar{w}[\lambda+(1-\lambda)(1+\varphi) \theta / \bar{\theta}]-w
$$

where $\varphi \equiv \alpha\left(1-\theta^{1 / \alpha}\right) \geq 0$ is the efficiency gain from social insurance. Hence $v(T ; w, \theta)$ is single-peaked in $T$ and preferences over taxation can be summarized by the type aggregator

$$
s(w, \theta, \lambda)=\frac{w}{\lambda+(1-\lambda)(1+\varphi) \theta / \bar{\theta}}
$$

where those with high $s$ prefers low tax and those with low $s$ prefer high tax. This type aggregator depends on the value of $\lambda$. If $\lambda=1$, tax proceeds are entirely redistributed in a lump sum way, and only income affects individual preferences for taxation. When $\lambda$ decreases, more tax revenue are used for insurance provision, and individual risk together with income affect preference for tax. At the limit, when $\lambda=0$, the type aggregator is the same (up to a multiplicative constant) as in the preceding sections $s(w, \theta, 0)=\bar{\theta} t(w, \theta)$.

We denote by $s_{m}$ the median value of this type aggregator. The Condorcet winning tax rate as a function of $\lambda$ is then given by

$$
T_{m}(\lambda)=1-\frac{s_{m}}{\bar{w}}
$$

and the resulting provision of insurance

$$
\delta_{m}(\lambda)=(1-\lambda) \frac{\bar{w}}{2 \bar{\theta}}\left(1-\left(\frac{s_{m}}{\bar{w}}\right)^{2}\right) .
$$

The Condorcet tax rate is affected by $\lambda$ through its effect on the median type, which depends on the joint distribution of income and risk. Increasing $\lambda$ has two effects on the provision of social insurance. First, a direct effect whereby with a higher $\lambda$ less tax revenue is available for social insurance. Second, an indirect effect, through the change in the identity of the median type. Evidently, if an increase in $\lambda$ induces a median type who prefers less taxation both effects reinforce each other and the provision of social insurance declines as $\lambda$ increases. Otherwise, the net effect is ambiguous.

We have performed numerical calculations to assess the influence of the joint distribution of risk and income on $T_{m}(\lambda), \delta_{m}(\lambda)$ and $G_{m}(\lambda)$ under the assumption that risk and income are independently distributed and risk uniformly distributed. Progressively increasing the positive skewness of the income distribution, we obtain : 
- When the skewness is small, $T_{m}(\lambda)$ is decreasing and $G_{m}(\lambda)$ is singlepeaked.

- When the skewness is high, $T_{m}(\lambda)$ is single-peaked and $G_{m}(\lambda)$ is increasing.

- For any skewness, $\delta_{m}(\lambda)$ is decreasing.

It follows, that the equilibrium level of social insurance declines when a larger fraction of tax revenue is used for redistribution. There is partial eviction between social insurance and direct redistribution.

We now turn to the preferences over $\lambda$. Differentiating the payoff with respect to $\lambda$, we obtain

$$
\frac{\partial v(T, \lambda ; w, \theta)}{\partial \lambda}=\left(1-\frac{T}{2}\right) T \bar{w}\left(1-\frac{(1+\varphi) \theta}{\bar{\theta}}\right) .
$$

Because this expression is independent of $\lambda$ voters have corner preferences on how to allocate tax revenue between redistribution and social insurace. . Moreover, their preference over $\lambda$ is also independent of the tax rate $T$ and $w$. This is due to the fact that once $T$ is chosen, the tax bill of the individual is fixed and the transfer received independent of individual characteristics. As a consequence, voters prefer to redistribute through social insurance if they benefit enough from it, i.e. if $\theta \geq \frac{\bar{\theta}}{(1+\varphi)}$. We then have that if $\theta_{m} \geq \frac{\bar{\theta}}{(1+\varphi)}$ there is a majority against income redistribution and $\lambda=0$. This will be the case if the risk distribution is not too positively skewed. In particular, without efficiency gain from social insurance, voters prefer social insurance to income redistribution if and only if their risk is higher than the average risk in the economy.

What can we say about a simultaneous vote over $T$ and $\lambda$ ? Multidimensional vote is very tricky, since it most often results in the absence of a Condorcet winner (see Plott, 1967). However, the structure of preferences we have here is very particular, since voters have corner preferences over $\lambda$ which are independent of $T$. We can conclude that, if $\theta_{m} \geq \frac{\bar{\theta}}{(1+\varphi)}$ and if a Condorcet winner exists, it involves $\lambda=0$ and $T_{m}(0)=1-\frac{s_{m}}{\bar{w}}$ where the type aggregator is the same (up to a multiplicative constant) as in the preceding sections: $s(w, \theta, 0)=\bar{\theta} t(w, \theta)$. That is, a majority prefers to redistribute through the provision of social insurance rather than through linear income taxation. Indeed, any policy bundle $\left(\lambda^{\prime}>0, T^{\prime}\right)$ is beaten at the majority by the policy bundle $\left(0, T^{\prime}\right)$. Moreover, any policy consisting of $\left(0, T^{\prime}\right)$ is majority beaten by $\left(0, T_{m}(0)\right)$. Unfortunately, we cannot conclude 
from this reasoning that a Condorcet winner exists since the policy bundle $\left(0, T_{m}(0)\right)$ may be defeated by another bundle when $\lambda$ is increased and the tax rate decreased simultaneously.

\section{Conclusion}

In this paper we have analyzed the political support for social insurance when individuals can buy additional private insurance on a voluntary basis. Social insurance is financed by a distortionary income tax and redistributes across income and risk levels. Private insurance is affected by adverse selection, which translates into partial coverage. Using a dual theory of preferences under uncertainty, we have shown that although individuals differ in two characteristics (income and risk), their preferences over social coverage can be summarized by a single parameter aggregating these two characteristics. Individuals with lower income and higher risk prefer more social insurance. We have also shown that introducing distortionary taxation results in at least some individuals preferring a mixed (social plus private) insurance system.

The classical two-party electoral competition game due to Downs assumes that both parties are only interested in winning the elections. We replace this assumption by another one that captures the important feature that parties also care about the utility of their members. This model, first proposed by Wittman(1973) and then later developed by Roemer(2001), further assumes that elections are inherently uncertain, (i.e. that parties cannot perfectly predict the electoral outcome once the platforms have been announced). Upon choosing their platforms, parties take into account both the utility their proposition will give to their members if implemented and the probability of winning the elections with this platform. Moreover, membership is also in equilibrium: given the platforms, no individual wants to change its membership.

In absence of electoral uncertainty, both parties would propose the Condorcet winner since it is the only way to affect the policy implemented. This is also the result of the Downsian electoral competition model. We calculate the endogenous parties Wittman equilibrium for different parameters values and show that more electoral uncertainty leads to more differentiation in the platforms. One party (that we call Left) represents the poor and the high risk individuals while the other one, dubbed the Right, represents rich and low risk people. If electoral uncertainty is not too high, equilibrium platforms are both interior and the equilibrium is symmetrical. That is, the 
median type is indifferent between the parties' proposals, each party ties for winning and the expected policy implemented is the Condorcet winner. Less electoral risk aversion further increases the divergence between platforms. Increasing the skewness of the income distribution leads both parties to propose a higher social insurance coverage rate, since more people benefit from the income redistribution underlying social insurance.

We then calibrate the model with US data from the Panel Study of Income Dynamics. We define the risk as the probability to incur medical care costs exceeding a threshold level (with two distinct thresholds). We obtain that the correlation between income and risk is slightly negative. Comparing the results obtained with the two thresholds for the damage, we obtain that the Condorcet winning coverage rate is lower when the damage threshold is higher, but the coverage rate proposed by the left party actually increases.

In the last section we study how the possibility of redistributing through linear income taxation would affect the political demand for social insurance. We have essentially two decision variables: the tax rate and the share of tax revenue redistributed through lump sum transfers. We find that increasing the share of tax revenue used for redistribution reduces the political demand for social insurance.

Acknowledgments. This paper has been presented at the First Workshop of the RTN Project on Financing Retirement in Europe (Barcelona, December 2002), Third Health Economics Workshop (Marseille, November 2002) and at seminars held at Universidad Autónoma Barcelona, Universidad Pompeu Fabra and Toulouse. We wish to thank especially Jean-Charles Rochet for his comments and Paula Lopes for suggesting the possibility of calibrating the model on PSID data. All remaining errors are ours.

\section{References}

[1] Blomqvist, A. and H. Horn, 1984, Public health insurance and optimal income taxation, Journal of Public Economics, 24, 352-71

[2] Börsch-Supan, A. and M. Miegel (Eds.), 2001, Pension reform in six countries: What can we learn from each other?, Berlin: Springer.

[3] Cremer, H. and P. Pestieau, 1996, Redistributive taxation and social insurance, International Tax and Public Finance, 3, 281-95.

[4] De Donder, Ph. and J. Hindriks, The politics of redistributive social insurance, forthcoming in Journal of Public Economics. 
[5] Gouveia, M. , 1997, Majority rule and the public provision of a private good, Public Choice, 93, 221-44.

[6] Mossin, J., 1968, Aspects of rational insurance purchasing, Journal of Political Economy, 76, 533-68.

[7] Petretto, A., 1999, Optimal social health insurance with supplementary private insurance, Journal of Health Economics, 18, 727-45.

[8] Plott, C.R., 1967, A Notion of Equilibrium and its Possibility under Majority Rule, American Economic Review, 57, 787-806

[9] Rochet, J.-C, 1991, Incentives, redistribution and social insurance, The Geneva Papers on Risk and Insurance Theory, 16, 143-65.

[10] Roemer, J., 2001, Political Competition. Theory and Applications, Harvard University Press.

[11] Shapiro, J., 1999, Income maintenance programs and multidimensional screening, mimeo, Department of Economics, Princeton University.

[12] Wittman, D., 1973, Parties as Utility Maximizers, American Political Science Review, 67, 490-498.

[13] Yaari, M., 1987, The dual theory of choice under risk, Econometrica $55, \mathrm{~N} 01,95-115$. 